\title{
Lateral-torsional buckling of ferritic stainless steel beams in case of fire
}

\author{
P. Vila Real ${ }^{1}$, N. Lopes ${ }^{1}$, L. Silva ${ }^{2}$ \& J.-M. Franssen ${ }^{3}$ \\ ${ }^{I}$ Department of Civil Engineering, University of Aveiro, Aveiro, Portugal \\ ${ }^{2}$ University of Coimbra, Coimbra, Portugal \\ ${ }^{3}$ Department ArGEnCo, University of Liege, Liege, Belgium
}

\begin{abstract}
This work presents a numerical study of the behaviour of ferritic stainless steel I-beams subjected to lateral-torsional buckling and compares the obtained results with the beam design curves of Eurocode 3. New formulae, for the lateral-torsional buckling, that approximate better the real behaviour of ferritic stainless steel structural elements in case of fire are proposed. These new formulae were based on numerical simulations using the program SAFIR, which was modified to take into account the material properties of the stainless steel. Keywords: ferritic, stainless steel, Eurocode 3, numerical modelling, lateraltorsional buckling, fire.
\end{abstract}

\section{Introduction}

There are five basic groups of stainless steels, classified according to their metallurgical structure: the austenitic, ferritic, martensitic, duplex austeniticferritic and precipitation-hardening groups [1]. Austenitic stainless steels provide a good combination of corrosion resistance, forming and fabrication properties. Duplex stainless steels have high strength and wear resistance with very good resistance to stress corrosion cracking. The most commonly used grades, typically referred to as the standard austenitic grades, are 1.4301 (widely known as 304) and 1.4401 (widely known as 316). The austenitic stainless steels are generally the more useful groups for structural applications but increasing interest in ferritic steels for structural purposes has been recently noted due to its low cost. The responsibility of the final cost of the austenitic stainless steel is the price of nickel. Typically they contain $8.0-13.0 \%$ of nickel whereas ferritic 
stainless steels contain a low nickel level. The ferritic stainless steel 1.4003 studied in this work contains $0.3-1.0 \%$.

The biggest advantage of stainless steel is its higher corrosion resistance. However, its easy maintenance, high durability and reduced life cycle costs are also important properties. It is also known that the fire resistance of stainless steel is higher than the carbon steel usually used in construction.

EN 1993-1-4 "Supplementary rules for stainless steels" [2] gives design rules for stainless steel structural elements at room temperature, only making mention to its fire resistance by doing referring to the fire part of the Eurocode 3, EN 1993-1-2 [3].

Although its use in construction is increasing, it is still necessary to develop the knowledge of its structural behaviour. Stainless steels are known by their non-linear stress-strain relationships with a low proportional stress and an extensive hardening phase. There is not a well defined yield strength, being usually considered for design at room temperature the $0.2 \%$ proof strength, $f_{\mathrm{y}}=f_{0.2 \text { proof. }}$. In a fire situation higher strains than at room temperature are acceptable, so Part 1.2 of Eurocode 3 suggests the use of the stress at $2 \%$ total strain as the yield stress at elevated temperature $\theta, f_{\mathrm{y}, \theta}=f_{2, \theta}$, for Class 1,2 and 3 cross-sections and $f_{\mathrm{y}, \theta}=f_{0.2 \mathrm{proof}, \theta}$, for Class 4 . Comparison of the reduction of strength and elastic stiffness of structural carbon steel and stainless steel at elevated temperature for several grades of stainless steels (as defined in EN 1993-1-2 [3]) is shown in figures 1 and 2, where $k_{\mathrm{y}, \theta}=f_{\mathrm{y}, \theta} / f_{\mathrm{y}}$ and $k_{\mathrm{E}, \theta}=E_{\theta} / E$, being $f_{\mathrm{y}, \theta}$ and $f_{\mathrm{y}}$ the yield strength at elevated temperature and at room temperature respectively, and $E_{\theta}$ and $E$ the modulus of elasticity at elevated temperature and at room temperature.

The stainless steel mechanical and thermal properties at high temperatures, used in this paper, can be found in Part 1-2 of Eurocode 3 [3]. For the evaluation of the yield strength reduction factor, the Eurocode states that the following equation should be used:

$$
k_{y, \theta}=\left[f_{0.2 p, \theta}+k_{2 \%, \theta}\left(f_{u, \theta}-f_{0.2 p, \theta}\right)\right] \frac{1}{f_{y}}
$$

where

$f_{0.2 \mathrm{p}, \theta}$ is the proof strength at $0.2 \%$ plastic strain, at temperature $\theta$;

$k_{2 \%, \theta}$ is the correction factor for determination of the yield strength $f_{\mathrm{y}, \theta}$;

$f_{\mathrm{u}, \theta}$ is the ultimate tensile strength, at temperature $\theta$.

Despite both carbon and stainless steel exhibiting different constitutive laws, whereby stainless steel presents a pronounced non-linear behavior even for low stress values, the stainless steel design rules are based on those developed for carbon steel. In a previous paper [4] a new proposal for the lateral-torsional buckling of austenic grades stainless steel beams was made. In the present paper a similar study is done for the ferritic stainless steel grade 1.4003 (the only ferritic stainless steel presented in Part 1.2 of the Eurocode 3).

Figure 1 shows that the variation of the strength reduction of the stainless steel grade 1.4003 with temperature is different from the other grades, mainly for the temperature range from $500^{\circ} \mathrm{C}$ to $700^{\circ} \mathrm{C}$. 


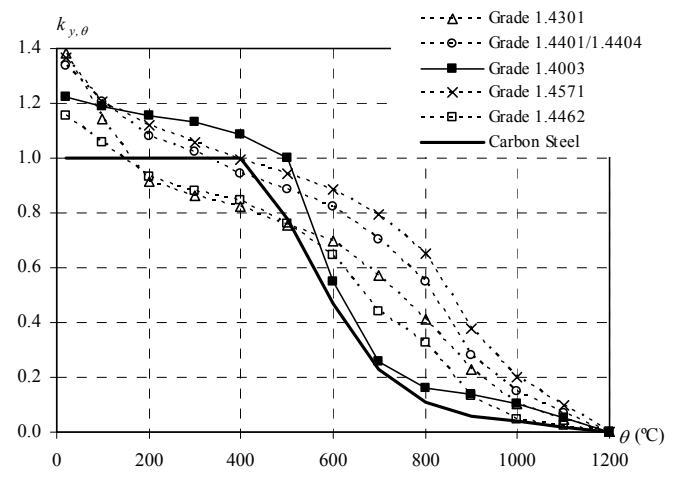

Figure 1: $\quad$ Strength reduction at high temperatures.

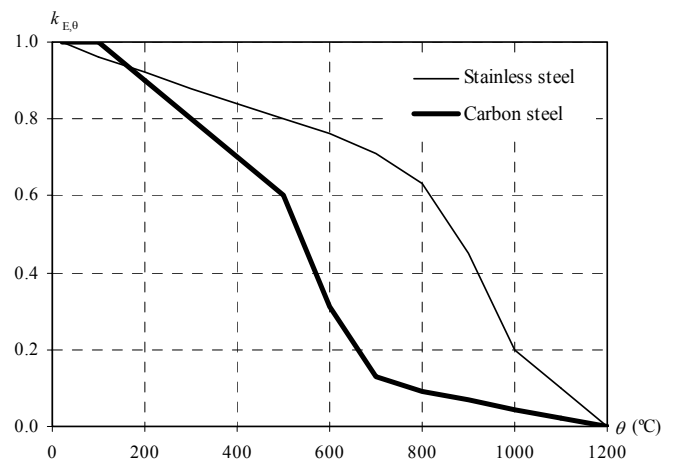

Figure 2: Elastic stiffness reduction at high temperatures.

The reduction of the yield strength and the reduction of the modulus of elasticity are used in the determination of the non-dimensional slenderness at high temperatures, as it will be shown later in this work.

Program SAFIR [5], a geometrical and material non linear finite element code, which has been adapted according to the material properties defined in EN 1993-1-4 [2] and EN 1993-1-2 [3], to model the behaviour of stainless steel structures [6] has been used in the numerical simulations. This program, widely used by several investigators, has been validated against analytical solutions, experimental tests and numerical results from other programs, and has been used in several studies that lead to proposals for safety evaluation of structural elements, already adopted in Eurocode 3. In the numerical simulations, geometrical imperfections and residual stresses were considered [4].

The objective of the study presented in this paper is to evaluate the accuracy of the lateral-torsional buckling design procedures prescribed in Eurocode 3, for I cross-sections in stainless steel grade 1.4003, at high temperatures. This study concluded that the Eurocode 3 formulae need to be improved and that a new proposal should be made for the stainless steel grade 1.4003 . 


\section{Case study}

A simply supported beam with fork supports subjected to uniform bending diagram was chosen to explore the validity of the beam safety verifications.

The influence of the cross-sectional shape, assessed using the height/width $(\mathrm{h} / \mathrm{b})$ relation, was taken into account in this work. Equivalent welded crosssections equivalent to an IPE220 (representative of $h / b=2$ ), HE500A (representative of $h / b<2$ ) and IPE500 (representative of $h / b>2$ ) were studied.

A uniform temperature distribution in the cross-section was used so that comparison between the numerical results and the Eurocode could be made. In this paper, the temperatures chosen were $400,500,600$ and $700{ }^{\circ} \mathrm{C}$, deemed to cover the majority of practical situations.

In the numerical simulations, a lateral geometric imperfection given by the following expression was considered:

$$
y(x)=\frac{l}{1000} \sin \left(\frac{\pi x}{l}\right)
$$

where $l$ is the length of the beam. An initial rotation around the beam axis with a maximum value of $l / 1000$ radians at mid span was also considered.

The adopted residual stresses follow the typical patterns for carbon steel welded sections, considered constant across the thickness of the web and flanges. The distribution is shown in Figure 3, and has the maximum value of $f_{\mathrm{y}}$ (yield strength) [7-9].

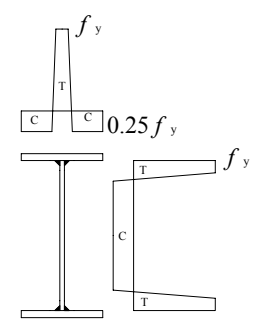

Figure 3: Residual stresses: $\mathrm{C}-$ compression; $\mathrm{T}-$ tension.

\section{Formulae for lateral-torsional buckling}

\subsection{Eurocode 3 formulae for stainless steel elements}

For stainless steel beams subjected to high temperatures, Part 1-4 of Eurocode 3 [2] states that the same formulation prescribed for carbon steel elements should be used, according to the EN 1993-1-2 [3], where the lateral-torsional buckling resistance for class 1 and class 2 cross-sections is given by

$$
M_{b, f i, t, R d}=\chi_{L T, f i} W_{p l, y} k_{y, \theta} f_{y} \frac{1}{\gamma_{M, f i}}
$$


where

$$
\chi_{L T, f i}=\frac{1}{\varphi_{L T, \theta}+\sqrt{\left(\varphi_{L T, \theta}\right)^{2}-\left(\bar{\lambda}_{L T, \theta}\right)^{2}}}
$$

with

$$
\varphi_{L T, \theta}=\frac{1}{2}\left[1+\alpha \bar{\lambda}_{L T, \theta}+\left(\bar{\lambda}_{L T, \theta}\right)^{2}\right]
$$

In this expression the imperfection factor $\alpha$ depends on the steel grade and is given by

$$
\alpha=\beta \sqrt{235 / f_{y}}=0.65 \sqrt{235 / f_{y}}
$$

The non-dimensional slenderness for lateral-torsional buckling at high temperatures is given by

being

$$
\bar{\lambda}_{L T, \theta}=\bar{\lambda}_{L T}\left[\frac{k_{y, \theta}}{k_{E, \theta}}\right]^{0.5}
$$

$$
\bar{\lambda}_{L T}=\sqrt{\frac{W_{p l, y} f_{y}}{M_{c r}}}
$$

where $W_{p l, y}$ is the plastic bending modulus, $f_{y}$ is the yield strength of steel and $M_{c r}$ is the elastic critical moment for lateral-torsional buckling.

\subsection{Proposal for austenitic and duplex stainless steel elements}

Figure 4 shows that the stainless steel beam design curve for lateral-torsional buckling from Eurocode 3 is not on the safe side. To improve this curve new severity factors $\beta$, given in table 1 , different from the one used for carbon steel (see equation 6), were proposed by the authors $[4,6]$. The new severity factor takes into account the influence of the shape of the cross-section. In this previous work the authors did not consider the influence of the stainless steel grade.

\section{Comparison between the lateral-torsional buckling formulae and the numerical results}

Application of eqs. (3) to (8) and Table 1 to ferritic stainless steels leads to the results of Figure 5, that compare the numerical results and the code proposals. It is clear that this proposal, based on austenitic stainless steels, is not accurate for ferritic stainless steels.

In this figure it can be observed that a beam with a length of $5 \mathrm{~m}$ exhibits slenderness values for $700^{\circ} \mathrm{C}$ and $600^{\circ} \mathrm{C}$ quite different from the corresponding values for $400^{\circ} \mathrm{C}$ and $500^{\circ} \mathrm{C}$. These differences are not so big for the case of austenitic stainless steel as shown in fig. 4. These differences result from the reduction of the yield strength (see fig. 1) is shown in fig. 6. As it can be seen in 
equation (7) the slenderness at room temperature is multiplied by the factor $\left(k_{\mathrm{y}, \theta} / k_{\mathrm{E}, \theta}\right)^{1 / 2}$ in order to obtain the slenderness at high temperatures. Figure 6 shows that from $500^{\circ} \mathrm{C}$ to $700^{\circ} \mathrm{C}$ there is a great decrease of this factor for the 1.4003 stainless steel, which does not occur with the others stainless steel grades.

Table 1: $\quad$ Values of the severity factor $\beta$.

\begin{tabular}{|l|c|c|}
\hline \multirow{2}{*}{ Cross-section } & Limits & $\beta$ \\
\hline \multirow{2}{*}{ Welded I section } & $\mathrm{h} / \mathrm{b} \leq 2$ & 0.85 \\
\cline { 2 - 3 } & $\mathrm{h} / \mathrm{b}>2$ & 1.00 \\
\hline
\end{tabular}



Figure 4: Lateral-torsional buckling in IPE 500 beams of the stainless steel grade 1.4301 .

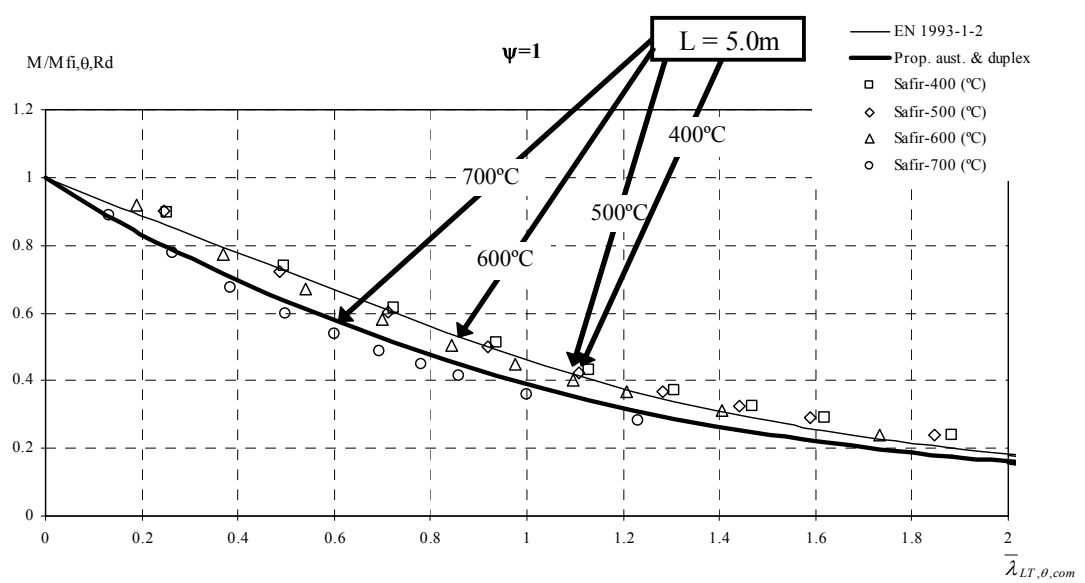

Figure 5: Lateral-torsional buckling for in IPE500 beams of the stainless steel grade 1.4003 . 


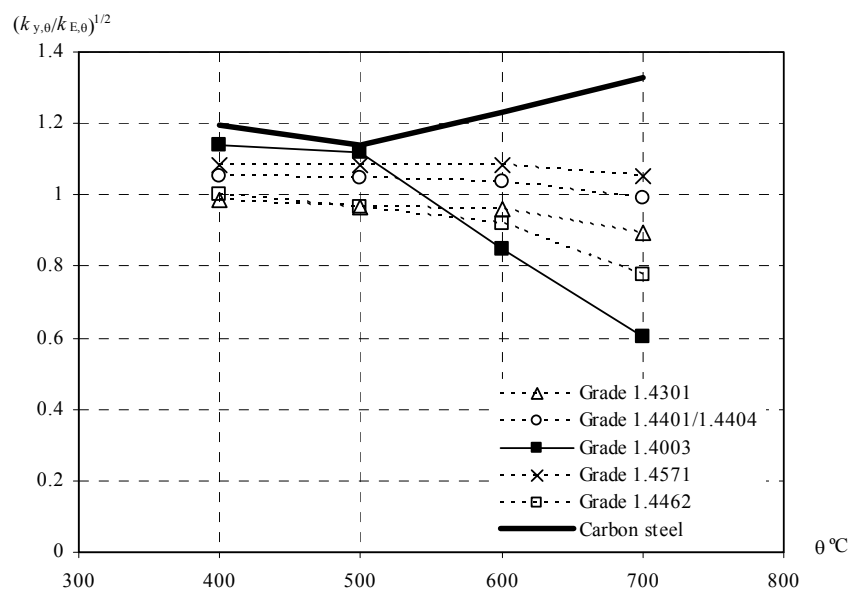

Figure 6: Variation of the square root used in the determination of the slenderness.

From figure 5 it can be concluded that the previous proposal [4] and the Eurocode 3 are not safe for the case of the ferritic stainless steel grade 1.4003. In the next section a new proposal covering ferritic stainless steel grades will be presented.

\section{New proposal for the ferritic stainless steel grade 1.4003}

Based on a parametric study considering the influence of the shape of the crosssection a new severity factor $\beta$, given in table 2 , was found for the stainless steel grade 1.403 .

Table 2: $\quad$ Values of the severity factor $\beta$ for the 1.4003 .

\begin{tabular}{|l|c|c|}
\hline \multirow{2}{*}{ Cross-section } & Limits & $\beta$ \\
\hline \multirow{2}{*}{ Welded I section } & $\mathrm{h} / \mathrm{b} \leq 2$ & 1.00 \\
\cline { 2 - 3 } & $\mathrm{h} / \mathrm{b}>2$ & 1.20 \\
\hline
\end{tabular}

Figures 7 to 9, compare the beam design curves obtained using Part 1-2 of Eurocode 3, described in section 3.1 of this paper (denoted "EN 1993-1-2"), the curve obtained with the new severity factor given in table 2 (denoted "New proposal"), and the numerical results obtained with the program SAFIR.

Table 3 summarizes the new severity factor taking into account the influence of the type of the stainless steel. 


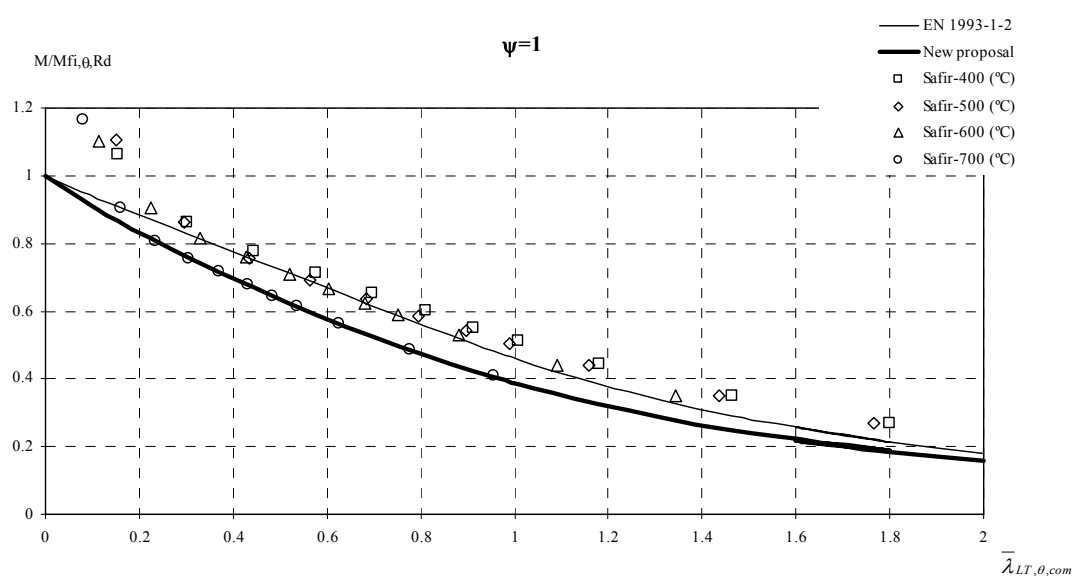

Figure 7: Lateral-torsional buckling in HE500A beams (representative of $\mathrm{h} / \mathrm{b}<2$ ) of the stainless steel grade 1.4003 .

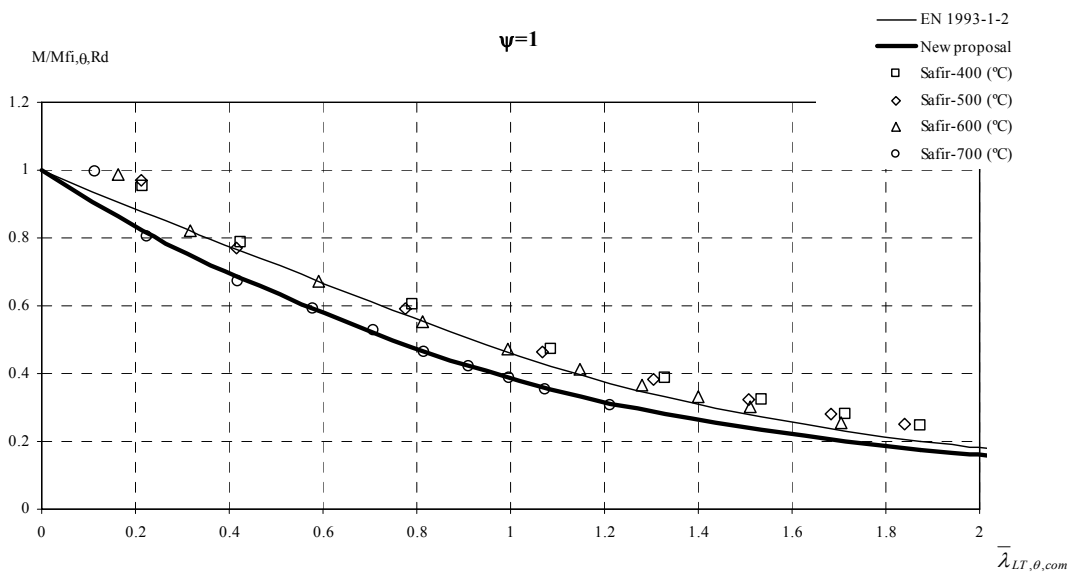

Figure 8: Lateral-torsional buckling in IPE220 beams (representative of $\mathrm{h} / \mathrm{b}=2$ ) of the stainless steel grade 1.4003 .

\section{Conclusions}

This paper has shown that the previous proposal made by the authors [4], for the lateral-torsional buckling resistance of unrestrained stainless steel beams under fire loading, based on the austenitic stainless steel, is not safe for the ferritic stainless steel grade 1.4003. A new severity factor that takes into account the influence of the steel grade, as well as the influence of the slenderness of the cross-section (relation $\mathrm{h} / \mathrm{b}$ of the cross-section) has been proposed being in good agreement with the numerical results obtained with the program SAFIR. This 
study also has shown that the slenderness of the cross-section should be taken into account as it is already proposed in Eurocode 3 for carbon steel elements at room temperature.

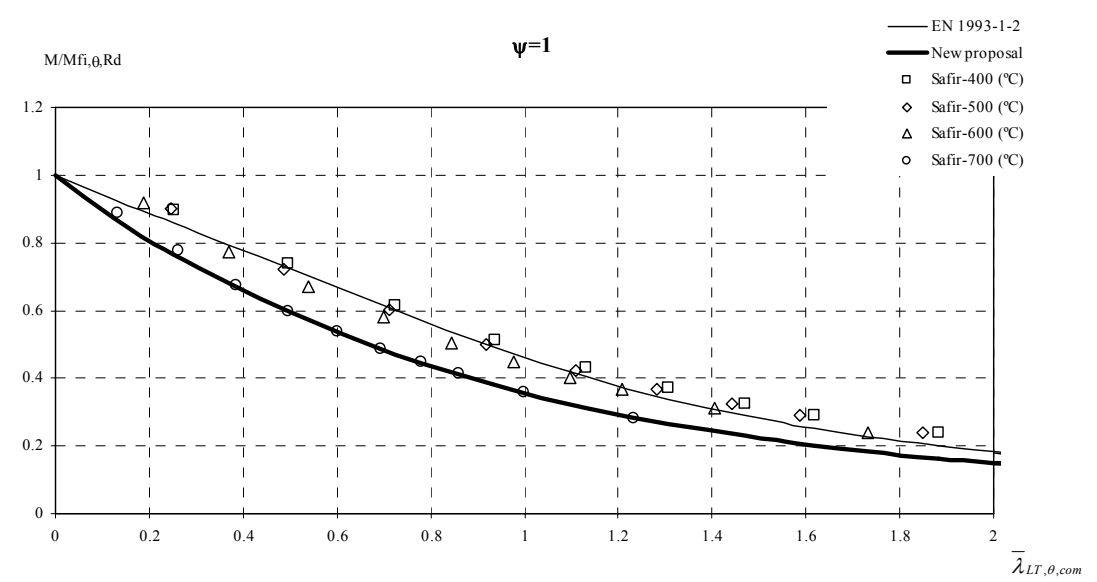

Figure 9: Lateral-torsional buckling in IPE500 beams (representative of $\mathrm{h} / \mathrm{b}>$ 2) of the stainless steel grade 1.4003 .

Table 3: $\quad$ New proposal for the severity factor $\beta$.

\begin{tabular}{|l|c|c|c|}
\hline \multirow{2}{*}{ Cross-section } & Limits & $\begin{array}{c}|c| \\
\text { Austenitic and } \\
\text { Duplex } \\
\text { stainless steel }\end{array}$ & $\begin{array}{c}\text { Ferritic } \\
\text { stainless steel } \\
1.4003\end{array}$ \\
\hline Welded I section & $\mathrm{h} / \mathrm{b} \leq 2$ & 0.85 & 1.00 \\
\cline { 2 - 4 } & $\mathrm{h} / \mathrm{b}>2$ & 1.00 & 1.20 \\
\hline
\end{tabular}

\section{Acknowledgement}

The authors wish to acknowledge the Calouste Gulbenkian Foundation (Portugal) for its supports through the scholarship given to the second author.

\section{References}

[1] Euro Inox e Steel Construction Institute "Design Manual for Structural Stainless Steel", $3^{\text {rd }}$ edition, 2006.

[2] European Committee for Standardisation, prEN 1993-1-4 "Eurocode 3, Design of Steel Structures - Part 1-4. General rules - Supplementary Rules for Stainless Steels”, Brussels, Belgium, 2005. 
[3] European Committee for Standardisation, EN 1993-1-2 "Eurocode 3: Design of Steel Structures - Part 1-2: General rules - Structural fire design", Brussels, Belgium, April 2005.

[4] Lopes, N.; Vila Real, P.; Silva, L.; Franssen, J.-M.; Mirambell, E. "Proposal to the Eurocode 3 for the lateral-torsional buckling of Stainless steel I-beams in case of fire" actas do Fourth International Workshop Structures in Fire SiF’06, pp. 463-472, ISBN 84-95999-74-9, Aveiro, Portugal, 10 to 12 of May of 2006.

[5] Franssen, J.-M. 2005. SAFIR. A Thermal/Structural Program Modelling Structures under Fire. Engineering Journal, A.I.S.C., Vol. 42, No. 3, pp. 143-158.

[6] Lopes, N., Vila Real, P.M.M., Piloto, P., Mesquita, L. e Simões da Silva, L., "Modelação numérica da encurvadura lateral de vigas I em aço inoxidável sujeitas a temperaturas elevadas", (in portuguese) Congreso de Métodos Numéricos en Ingeniería, Granada, Spain, 2005.

[7] Chen W. F. and Lui E. M. Stability design of steel frames. CRC Press, 1991.

[8] Gardner, L., Nethercot, D. A. 2004. Numerical Modeling of Stainless Steel Structural Components - A consistent Approach. Journal of Constructional Engineering, ASCE, pp. 1586-1601.

[9] Greiner, R.; Hörmaier, I.; Ofner, R.; Kettler, M., 2005. Buckling behaviour of stainless steel members under bending. ECCS Technical Committee 8 - Stability. 